Canadian Journal of Civil Engineering

Canadian

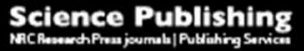
Revue canadienne de génie civil

\title{
Evaluation of Bitumen Physical Properties Modified with Waste Plastic Pipes
}

\begin{tabular}{|r|l|}
\hline Journal: & Canadian Journal of Civil Engineering \\
\hline Manuscript ID & cjce-2017-0672.R1 \\
\hline Manuscript Type: & Article \\
\hline Date Submitted by the Author: & 09-Feb-2018 \\
\hline Complete List of Authors: & $\begin{array}{l}\text { Köfteci, Sevil; Akdeniz University, Civil Engineering Department } \\
\text { Ahmedzade, Perviz; Ege Universitesi } \\
\text { Günay, Taylan; Ege Universitesi }\end{array}$ \\
\hline $\begin{array}{r}\text { Is the invited manuscript for } \\
\text { consideration in a Special } \\
\text { Issue? : }\end{array}$ & Not Applicable (Regular Submission) \\
\hline Keyword: & Modified bitumen, ground plastic pipe, HDPE wastes, Recycling \\
\hline & \\
\hline
\end{tabular}




\title{
EVAULATION OF BITUMEN PHYSICAL PROPERTIES MODIFIED WITH WASTE PLASTIC PIPES
}

\section{Sevil Köfteci*}

Department of Civil Engineering, Akdeniz University, Antalya, Turkey

\section{Perviz Ahmedzade}

Department of Civil Engineering, Ege University, Izmir, Turkey

\section{Taylan Günay}

Department of Civil Engineering, Ege University, Izmir, Turkey

\begin{abstract}
The aim of this paper is to examine the effects of ground plastic pipe wastes on the bitumen For this purpose, three modified bitumen with the modifier content $2 \%, 4 \%$ and $6 \%$ and pure bitumens were prepared and tested. In order to understand effect of modifier on bitumen, conventional bitumen tests, rotational viscosity tests (RV) at the $135{ }^{0} \mathrm{C}$ and $165{ }^{\circ} \mathrm{C}$, Dynamic Shear Rheometer tests (DSR) at three different frequencies which are represent three different traffic speeds and Bending Beam Rheometer Test (BBR) were performed. BBR test results showed that, resistance of pure bitumen against to low-temperature cracking increased by using additives up to $4 \%$. Based on the results of this study, it can be said that waste plastic pipes can be used as modifier for the bitumen binder. Additive by $4 \%$ especially showed the best performance.
\end{abstract}

Keywords: Modified bitumen, ground plastic pipe, HDPE wastes, recycling

* Corresponding Author:

Department of Civil Engineering, Akdeniz University, Antalya, Turkey

Phone: +90(505) 2757232

Fax: +90(242) 3106366

E-mail: skofteci@akdeniz.edu.tr 


\section{Introduction}

Bitumen is a dark black semisolid material, obtained from the atmospheric and vacuum distillation of crude oil during petroleum refining (Maashanand Karim 2013). The behavior of bitumen varies depending on vehicle speed and temperature. This property causes deterioration of bitumen. One major type of modifier that has found inward acceptance in the profession is the polymer modified bitumen (PMB) (Topal, 2010).Polymers are widely used for improving the properties of bitumens (Solouki et al. 2015; Oner et al. 2016; Rossi et al. 2015).However, when constructing pavements, modifying the bitumen with polymer-based additives leads to a significant rise in construction costs. Using polymer-based waste materials instead of polymer-based additives in modifying bitumens is not only a more economic approach, but also presents a significant benefit to society from an environmental perspective. A review of studies using polymer-based waste as a modifier for bitumens reveals that these materials contribute to the bitumen's properties in various ways (Silva et al. 2015; Garcia-Morales et al., 2006).Due to the widespread use of plastics which is a type of a polymer, plastic based wastes are increasing throughout the world. Plastic materials can modify bitumens, depending on their own chemical and physical properties (Kofteci et al. 2014). As plastic-based waste materials do not breakdown and disappear in nature, it is essential that these materials are economically reutilized through recycling. Modarres and Hamedi (2014) analyzed the effect of waste plastic bottles on the stiffness and fatigue properties of modified asphalt mixes. They found that, bitumen modified with waste polyethylene terephthalate (PET) showed same behavior at $20{ }^{\circ} \mathrm{C}$ bitumen modified with styrene-butadiene-styrene (SBS) especially in terms of flexibility and fatigue behavior. Hasan et al. (2016) used three types of electronic waste (e-waste) plastics as a modifier in bitumen. The study concluded that use of chemically treated e-waste modifiers significantly improved the resistance to rutting of asphalt bitumens. High-density polyethylene (HDPE) is a hard plastic-type and is widely used in the world. In order to benefit from its hardness feature and reduce wastes, HDPE used as a modifier not only for bitumen but also for asphalt mixture in some experimental studies. The effects of HDPE and crumb rubber powder (CRP) on the properties of hot mix asphalt were investigated by Gibrel and Feng (2017). Modified and unmodified bitumen properties were investigated. Then Marshall stability and flow, Marshall quotient, moisture sensitivity, and wheel tracking (rutting) tests were also conducted. The results showed that using HDPE and CRP as modifiers improves the physical properties of asphalt and Marshall properties of HMA mixtures. Nejad et al (2014) investigated on effect of high density polyethylene on the fatigue and rutting performance of hot mix asphalt. The results indicated HDPE increases the adhesion between the asphalt binder and the aggregate in the presence of moisture. HDPE and PET pellets were used as fine aggregate in asphalt mixtures by Rahman et al 
(2014). In this study, engineering properties such as stiffness, permanent deformation and fatigue behaviour of modified asphalts were determined by using Asphalt Testing System. In conclusion, they suggested the $10 \%$ HDPE modified asphalt could consider comply with all engineering properties requirement.

This paper presents a laboratory evaluation about fundamental rheological characteristics of the bitumen modified with recycled ground plastic pipe wastes. Wastes used in the study were chosen from HDPE based pipes. To this end, waste materials were obtained from a recycling facility in Antalya in powder form. The changes in the properties of pure and modified bitumens before aging and after aging with rolling thin film oven test (RTFOT) were determined using conventional bitumen tests. The change in the workability of the bitumen was then measured using the RV test. Finally, the rheological behaviour of pure and modified bitumen samples were studied by DSR tests at different frequencies and BBR tests at different low temperatures.

\section{Materials and Methods}

\subsection{Materials}

The pure bitumen with a 160-220 penetration grade was obtained from Turkish Petroleum Rafineries Corporation (TUPRAS). Table 1 gives a properties of pure bitumen obtained from conventional bitumen tests.

Table 1.Physical properties of the pure bitumen

The plastic wastes used in the study were all HDPE-based. HDPE type plastic uses in many areas such as food industry, irrigation sector etc. HDPE is a high-density polyethylene material, and is fairly rigid compared with other polymer materials. HDPE a rigid and water-resistant petroleum derived product that has higher tensile and compressive strength compared with other plastics (Hsuan and McGrath 1999). For this reason, it is widely used in agricultural sector, drinking water and natural gas pipes of infrastructure facilities. HDPE is obtained through the polymerization of ethylene at low temperature and pressure with the aid of various catalysts. In Turkey, especially in Antalya, the agricultural and construction sector is very large. HDPE uses in both sector widely. For this reason, waste pipes that have completed their life create large environmental waste. Waste ground plastic pipes used in this study were obtained from a recycling facility in Antalya. The HDPE containing pipes used in the study are waste pipe materials that were once used in water lines. The basic characteristics of HDPE used in the experimental study as additive are given in Table 2.

Table 2. Basic physical properties of the HDPE additive 


\subsection{Preperation of samples}

Plastic pipe wastes in powder form was sieved the by using the 75 micron sieve, in order to obtain modifier with the necessary thinness for the performed experimental study. Samples were prepared by using the waste plastic pipes at $0 \%, 2 \%, 4 \%$ and $6 \%$ of bitumen weight. After heating bitumen at $155{ }^{\circ} \mathrm{C}$ in the laboratory type oven, it was poured into the mixing vessel. Following this, the modifier was carefully added to the pure bitumen. Bitumen and modifier were mixed in the mixer at $400 \mathrm{rpm}$ speed for almost 15 minutes, until the mixture temperature raised $180^{\circ} \mathrm{C}$. After reaching this temperature, the speed of mixer was raised to $1100 \mathrm{rpm}$ and the modifying process was continued for 60 minutes. Finally; small containers were filled with the samples, which were covered by using aluminum foil, and then stored for use in the other experimental studies.

Samples were coded as follows:

- Pure bitumen- "B";

- Pure bitumen + $2 \%$ waste pipe - "B-2-WP";

- Pure bitumen + 4 \%waste pipe- "B-4-WP";

- Pure bitumen $+6 \%$ waste pipe- "B-6-WP";

\subsection{Experiments}

Conventional tests were used to determine the physical characteristics of the bitumen before and after aging. In order to ensure the stability and the resistance to separation of modified binders during mixing, handling and in service, the compatibility test was also applied throughout storage stability test according to EN 13399 standard. The test was conducted on modified bitumens a preheated oven in $170^{\circ} \mathrm{C}$ for $72 \mathrm{hr}$. After storing of samples in oven, samples were left to cool at room temperature, and then cut into three parts. The top and bottom parts were tested to evaluate the storage stability by measuring their penetration, softening point, and comparing results of each test between the two parts (EN 13399-2010).

In order to determine the change in the workability of the bitumen under the effect of the modifier, rotational viscosity test was performed at two different temperature $\left(135{ }^{\circ} \mathrm{C}\right.$ and $\left.165{ }^{0} \mathrm{C}\right)$. The complex shear modulus $\left(\mathrm{G}^{*}\right)$ and phase angle values $(\delta)$ were calculated to determine viscoelastic behaviours of bitumen samples at the $0.111 \mathrm{~Hz}, 0.796 \mathrm{~Hz}$ and $1.909 \mathrm{~Hz}$ frequencies which are representig three different speed values low $(7 \mathrm{~km} / \mathrm{h})$, medium $(50 \mathrm{~km} / \mathrm{h})$ and high $(120 \mathrm{~km} / \mathrm{h})$ using the dynamic shear rheometer. Temperatures sweeps $\left(25-70{ }^{0} \mathrm{C}, 25 \mathrm{~mm}\right.$. parallel plate, $1 \mathrm{~mm}$. gap) with $5{ }^{0} \mathrm{C}$ increments were applied at a different frequency and controlled strain. Finally, in order to identify performance of bitumen in all weather conditions, bitumen must be 
tested each temperature values. In the opinion of Strategic Highway Research Program(SHRP) researchers, usage of DSR device is not suitable to measure bitumen properties at low temperatures ( from $0{ }^{\circ} \mathrm{C}$ to $-36{ }^{\circ} \mathrm{C}$ ) (Lu and Isacsson, 1997). A typical service ability loss occurs when the formation of ruts forces the pavement to crack, which can lead to rapid deterioration of the pavement due to the accumulation of water on the pavement surface (Tapkın et al.2012). For this reason, rutting parameters of pure and modified samples and calculated for each temperature. The bending beam rheometer (BBR) test is used to analyze the behaviour pure and modified under low temperatures. The BBR test would allow the determine thermal cracking (low-temperature cracking) possibility of bitumen under low temperatures. The BBR test was performed in accordance with the procedures described in ASTM D6648-01 in this study. During testing, the bitumen beams (125 mm. long, $12.5 \mathrm{~mm}$. wide and $6.25 \mathrm{~mm}$. thick) were immersed in a bath at a certain temperature and the test temperature was not changed for $60 \mathrm{~min}$. The load which has a $100 \mathrm{~g}$ weight was applied to the bitumen beam. The beam was supported at both ends. The deflection of center point was measured. Determined deflection value was used for the measure creep stiffness and creep rate parameters at several loading times. In order to obtain an enough low temperature cracking resistance for bituminous binder, creep stiffness value must be less than $300 \mathrm{MPa}$ and the m-value must be greater than 0.3 (Nichols 2006).

\section{Results and discussion}

\subsection{Conventional Bitumen Test Results}

Table 3 shows the results obtained from the conventional tests, conducted on samples that were pure and modified bitumen samples with pipe wastes at $2 \%, 4 \%$ and $6 \%$.

Table 3.Conventional test results of the pure and WP modified bitumens before and after aging

An evaluation of the penetration test results indicates that increasing the amount of waste pipe additives leads to a decrease in penetration values. This decrease is particularly notable in the bitumen with $6 \%$ additive. While the penetration value of the pure bitumen is 196.3 , the addition of $6 \%$ additive decreased this value to 71.4, so it can be said that, the bitumen hardened excessively. A comparison between additive materials shows that when the additive ratio is increased from $2 \%$ to $4 \%$, the resulting hardening is more than two times greater than the hardening observed when the additive ratio is raised to $6 \%$. In other words, using $6 \%$ additive material led to a sudden and dramatic increase in hardening. The addition of waste HDPE to the pure bitumen at a ratio of $6 \%$ raised the softening point from $41.2^{\circ} \mathrm{C}$ to $62.4{ }^{\circ} \mathrm{C}$. The addition of waste HDPE to the pure bitumen at a ratio of $6 \%$ raised the softening point from $41.2^{\circ} \mathrm{C}$ to $62.4{ }^{\circ} \mathrm{C}$. Both of these results can be explained by the excessive 
hardening of the modified binder. On the other hand, the decrease in ductility values can be explained by the decrease in extensibility that results from the hardening caused by the addition of additive materials in higher ratios.

The adding of additives to the bitumen led to a general decrease in the sensitivity to temperature which are represented with penetrationindex. As shown in Table 3, A modification process involving up to $4 \%$ additives reduced the temperature sensitivity of the bitumen. Thus, an increase in the amount of additive added to the bitumen was associated with an increase in the temperature interval in which the bitumen could be used. As shown in Table 3, when the ratio of additive material in the bitumen increased to $4 \%$, a paralel increase took place in the penetration index value, while at $6 \%$, the penetration index value began to decrease. A modification process involving up to $4 \%$ additives reduced the temperature sensitivity of the bitumen. Thus, an increase in the amount of additive added to the bitumen was associated with an increase in the temperature interval in which the bitumen could be used. Meanwhile, B-6-WP exhibited a higher penetration index value than pure bitumen. Modified bitumen with such a ratio of pipe waste was less sensitive to temperature than the pure bitumen. Nevertheless, in terms of ensuring the broadest temperature range over which the bitumen could be used, the optimum additive ratio was $4 \%$. Results obtained from RTFOT test reveals that, with regards to penetration values, the modified bitumen underwent a higher level of hardening than the pure bitumen. An evaluation of the mass loss values resulting from the aging process reveals that the level of mass loss was below the upper limit of $1 \%$.

\subsection{Storage StabilityTest Results}

During long storage process of binder, it could lead to phase separation of binder and poor stability problems. This problem becomes major in modified binder industry. Table 4 shows that both penetration and softening point results of top and bottom parts of WP modified bitumens tested in storage stability test are very close to each other. This gives a good indication about consistency and homogeneity of WP modified bitumens.

Table4. Storage stability test results of WP modifiedbitumens.

\subsection{Rotational Viscosity (RV) Test Results}

Rotational viscosity test results performed at $135^{\circ} \mathrm{C}$ and at $165^{\circ} \mathrm{C}$ with pure and waste HDPE-modified bitumens are shown in Table 5. Based on the obtained results, compaction as well as mixing temperature values were calculated for the bituminous hot mix asphalt by using the viscosity indices and the viscosity values. 
Table 5. Viscosity values of the pure and WP modified bitumens

Table 5 shows that, adding increasing amounts of waste HDPE to the pure bitumen has the effect, at both temperatures, of noticeably increasing the viscosity value of the modified bitumencompared with that of the pure bitumen. Limit viscosity value ( 3 Pa.s at $135{ }^{\circ} \mathrm{C}$ ) was not exceeded accordingto AASHTO M320. This means that higher ratios of modifier resulted in increased hardening for the bitumen. This, in turn, decreases the bitumen's workability. An evaluation of the change in the viscosity values shows that, for both temperature values, the increase in viscosity is really dramatic for the $6 \%$ HDPE additive ratio. For example, while the addition of $2 \%$ waste $\mathrm{HDPE}$ at $135^{\circ} \mathrm{C}$ increases the pure bitumen's viscosity value from $207.5 \mathrm{cPto} 225 \mathrm{cP}$, the addition of $6 \%$ waste HDPE has raised the viscosity value to $467.5 \mathrm{cP}$. This value is 2.25 times the viscosity value of the pure bitumen.

The mixing and compaction temperature values in Figure 1 shows that, comparedwiththe pure bitumen, thesevalueshaveoccurredconsiderableincreaseforthemodifiedbitumenwith $6 \%$ HDPE additive. In other words, an increase in the ratio of modifier added to the pure bitumen has resulted to a paralel increase in the mixture and compaction temperature values, and, by extension, in the amount of energy expended for these processes. When the additive ratio is raised to $6 \%$, the mixing temperature range begins at $180^{\circ} \mathrm{C}$. The fact that the mixture and compaction temperature range of the HMA has such a high value indicates that the production and paving/laying stages of the mixture requires an excessive amount of energy, and that, by extension, the use of these bitumens entails a higher level of environmental pollution. This is an undesirable outcome. In addition, when preparing the HMA for this temperature value, the bitumen rapidly aged above a temperature of $180{ }^{\circ} \mathrm{C}$, causing it to lose its properties (Wang et al.2013). For this reason, using a 6\% additive ratio for modifying the bitumen led to highly negative results.

Figure 1. The mixing-compaction temperatures for pure and WP modified bitumens

\subsection{Dynamic Shear Rheometer (DSR) Test Results}

Wheel tracking deformations are especially significant under traffic conditions with considerable heavy vehicle traffic. For this reason, it is important to determine bitumen performance at low speeds, which are representative of heavy vehicle traffic In order to analyze the susceptibility of modified binders to permanent deformation in terms of rutting, DSR tests were performed The DSR experiments were performed according to the parameters provided in Table 6 .

Table 6. Test parameters used in the DSR test 
Wheel tracking parameters $(\mathrm{G} / \mathrm{sin} \delta)$ were calculated by using complex shear modulus $\left(\mathrm{G}^{*}\right)$ and phase angle $(\delta)$. Complex shear modulus shows the total resistance of bitumen against to the shear stress. Phase angel, as well, is an indication of viscous deformation of the bitumen relative to elastic deformation.

Figure2showsthechange in complex shear modulus according to temperature at low speeds. An evaluation of this figure reveals that a B-6-WP is associated with a particularly high increase in the complex shear modulus value; namely, a $6 \%$ modification of the bitumen resulted in a hardening of the bitumen. As the complex shear modulus tends to decrease with increasing temperatures, higher temperatures can cause wheel tracking deformations on flexible pavements. For this reason, the decrease in the complex shear modulus is especially important at temperature above $40-45^{\circ} \mathrm{C}$. B and B-6-WP have rapidly decreasing complex shear modulus values with higher temperatures, while the decrease in the complex shear modulus is comparatively slower (and the slope value lower in figure) for the B-2WP and B-4-WP. At higher temperature values of 60$65^{\circ} \mathrm{C}$, the $4 \%$ modified bitumen, in particular, exhibited nearly as much shear resistance as B-6-WP

Figure 2. Complex shear modulus $\left(\mathrm{G}^{*}\right)$ for WP modified bitumens at $0.111 \mathrm{~Hz}(7 \mathrm{~km} / \mathrm{h})$

Figure 3 and 4 shows the complex shear modulus for medium and high traffic speeds, and indicates that modifying the pure bitumen at a ratio of $6 \%$ has led to a considerable increase in the complex modulus values. Conversely, $2 \%$ and $4 \%$ modified bitumens gave complex modulus values that were fairly close to one another at low and high temperatures. Phase angle is an indicator of the relative level of viscous and elastic response/behavior of the asphalt binders.

Figure 3. Complex shear modulus $\left(\mathrm{G}^{*}\right)$ for $\mathrm{WP}$ modified bitumens at $0.796 \mathrm{~Hz}(50 \mathrm{~km} / \mathrm{h})$

Figure 4. Complex shear modulus $\left(\mathrm{G}^{*}\right)$ for WP modified bitumens at $1.909 \mathrm{~Hz}(120 \mathrm{~km} / \mathrm{h})$

Phase angle values are an indicator of the relative level of viscous and elastic deformation in the bitumen. As such, the phase angle illustrates the viscoelastic behaviors of the bitumen against shear stresses. Figure 5, 6 and 7 shows that the phase angle values have a decreasing trend with the B-2-WP and B-4-WP. At these ratios of modification, the modified bitumens exhibited improved viscoelastic properties compared with the pure bitumen. Adding these ratios of additives to pure bitumen not only served to hardened the bitumen, but it also did not have any negative effects on the bitumen's elastic properties. Thus, these modified bitumens displayed improved resistance against permanent deformations. Since the deformations that occur under these conditions are fully reversible, these bitumens acts as an elastic solid; however, modifying the bitumen by $6 \%$ resulted in a sudden increase in the phase angle, reducing the elasticity of the bitumen. An evaluation of the 
complex shear modulus values at this speed level shows that a $6 \%$ modification ratio led to a very high increase in the complex shear modulus values. In other words, the bitumen gained resistance against shear stresses. Results from conventional test results and rotational viscometer tests also support these results. Thus, while the use of $6 \%$ additive led to a considerable hardening of the bitumen, thislevel of hardening has, according to the phase angle values, also led to a loss of bitumen elasticity.

An increase in phase angle in paralel to a temperature increase is expected, since bitumens exhibited a more viscous behavior at higher temperatures compared to lower temperatures. An evaluation of the phas eangle - temperature graph for low speed traffic in Figure 5, which is representative of heavy vehicle traffic, reveals that increasing temperature led to higher phase angles for the $2 \%$ and $6 \%$ modified bitumens. On the othe rhand, the phase angle of B-4-WP exhibited a lower level of tendency to increase with higher temperatures. At very high temperatures in particular, the phase angle of the B and B-6-WP reaches nearly 40 degrees, meaning that the bitumens almost become fully viscous, while B-4-WP experience relatively lower increases in their phase angles at very high temperatures. Compared with the pure bitumen and the bitumens with different ratios of modification, B-4-WP was better able to preserve its viscoelastic structure under high speed heavy vehicle traffic, and was as a result more resistant against permanent deformations. Nonetheless, while the $2 \%$ modified bitumen led to a slight improvement in terms of elastic properties when compared with the pure bitumen, its phase angle values were particularly high at higher temperatures, meaning that the level of contribution/benefit it provided, relative to the pure bitumen, was fairly limited.

Figure 5.Phase angel $(\delta)$ for WP modified bitumens at $0.111 \mathrm{~Hz}(7 \mathrm{~km} / \mathrm{h})$

In Figure 6 and 7, which shows the effects of medium and high speed traffic, it can be seen that the use of $4 \%$ additives led to a considerable decrease in the phase angle value relative to the pure bitumen, and that, for this modification ratio, the level of increase observed in the phase angle at high temperatures and high speed traffic was higher when compared with the level of observed in the phase angle at low speed traffic. Thus, at higher speeds, the use of $4 \%$ additives in the bitumen did not contribute as much to the bitumen's elasticity as it did at lower speeds.

Figure 6.Phase angel $(\delta)$ for WP modified bitumens at $0.796 \mathrm{~Hz}(50 \mathrm{~km} / \mathrm{h})$

Figure 7.Phase angel $(\delta)$ for WP modified bitumens at $1.909 \mathrm{~Hz}(120 \mathrm{~km} / \mathrm{h})$ 
Figures 8-10 shows the change according to temperature and at different frequencies in the wheel tracking parameters of the pure bitumen and the bitumens with three modifications at different ratios. An evaluation of the wheel tracking parameter indicates that, at all three frequencies, an increase in the ratio of additive (or modification) was associated with an increase in wheel tracking. Figure 8 shows that the increase in the wheel tracking parameter value at a frequency of $0.1 \mathrm{~Hz}$, which represents heavy vehicle traffic, is greater than the value observed at the other frequencies. In particular, the level of increase becomes more significant at higher temperatures. Although the increase in wheel tracking value was greater for the middle frequency compared with the higher frequency, it was observed that at both frequencies, modifying the bitumen with higher ratios of additives increased the bitumen's resistance to wheel tracking deformation. This finding suggests that using waste HDPE as an additive in bitumens may help to prevent wheel tracking deformations under high temperature and heavy traffic conditions.

Figure 8.Rutting parameters $\left(\mathrm{G}^{*} / \mathrm{sin} \delta\right)$ for WP modified bitumens at $0.111 \mathrm{~Hz}(7 \mathrm{~km} / \mathrm{h})$

Figure 9.Rutting parameters $\left(\mathrm{G}^{*} / \mathrm{sin} \delta\right)$ for WP modified bitumens at $0.796 \mathrm{~Hz}(50 \mathrm{~km} / \mathrm{h})$

Figure 10.Rutting parameters $\left(\mathrm{G}^{*} / \sin \delta\right)$ for WP modified bitumens at $1.909 \mathrm{~Hz}(120 \mathrm{~km} / \mathrm{h})$

According to the results of all the DSR tests, modifying the pure bitumen with increasing ratios of waste HDPE has the effect of improving the bitumen's complex shear modulus and wheel tracking parameter. However, an evaluation of the phase angle values shows that the use of $4 \%$ additive improves the bitumen's elasticity properties. However, modifying the bitumen at a ratio of $6 \%$ instead leads to a loss of elasticity. A $4 \%$ ratio modification increases the bitumen's elastic properties and resistance against wheel tracking deformations, especially under heavy traffic and high temperature conditions.

\subsection{Bending Beam Rheometer (BBR) Test Results}

To measure the resistance against thermal cracks of the pure and modified bitumen, BBR tests were performed at negative temperature values. The tests were carried out under different loading times $(8,15,30,60$, 120 and $240 \mathrm{~s}$.$) and temperature \left(-15,-25\right.$ and $\left.-35^{\circ} \mathrm{C}\right)$ conditions. Table 7 shows the creep stiffness and $m$ values at three different temperatures and $60 \mathrm{~s}$. loading times.

Table 7. Creep stiffness and $m$-value of the pure and modified bitumens at a loading time $60 \mathrm{~s}$ and different temperatures 
As shown in this Table 7, the creep stiffness values of the bitumens modified with waste HDPE was lower when compared with the pure bitumen, while their m-values were higher. Thus, the modification of the bitumen had a positive effect in terms of low temperature performance. A comparison of the bitumens with different ratios of modification shows that the use from $2 \%$ to $4 \%$ additive decreased the creep stiffness value, while the use of $6 \%$ additive increased it. Thus, the improvement in low temperature performance was observed up to a modification ratio of $4 \%$. Although the low temperature performance slightly decreased when the ratio of additive was increased to $6 \%$, performance at this modification ratio was still higher when compared with the pure bitumen. In addition to this, the use of $6 \%$ additive led to a sudden and dramatic increase in hardening, which in turn resulted in a decrease in low temperature performance (in contrast to the improvement observed with the two lower percentage ratios). Therefore, the B-6-WP became more susceptible to low temperature fractures in comparison with the $2 \%$ and $4 \%$ modified bitumens.

\section{Conclusions}

In this study, the effect of using grounded waste HDPE additive in bitumen with 160-220 penetration was investigated in order to determine usability of waste material for recycling. The use of additives at the increasing ratio generally tended to increase the bitumen's hardening. The most hardening was observed at a modification ratio of $6 \%$. Penetration index values showed that, the modification of the bitumen decreased its sensitivity to temperature. The $4 \%$ modified bitumen had the least sensitivity against temperature especially. The storage stability test revealed that WP is highly stable with bitumen and has no phase separation problems during long time of storage process.

According to the RV test results, the modification of the bitumen with waste HDPE led to a continuous increase in viscosityvalues at bothtemperatures $\left(135^{\circ} \mathrm{C}\right.$ and $\left.165^{\circ} \mathrm{C}\right)$ levels. Relative to the pure bitumen, the use of $6 \%$ additive led to an even greater increase in viscosity at both temperatures. This, in turn, might cause a bitumen with this ratio modification to have a mixing temperature above $180^{\circ} \mathrm{C}$. Such a high mixing temperature will not only lead to greater energy costs and pollution, but also cause the bitumen to age at a faster rate. These findings indicate that modifying the bitumen with this ratio of additive will not have positive effects on the bitumen properties.

According to the DSR test results, increasing the ratio of waste HDPE additive in the bitumen to $2 \%$, $4 \%$ and $6 \%$ compared with the pure bitumen, led to an increase in the complex shear modulus and Wheel tracking parameter values at all three different speed levels. Thus, increasing the ratio of bitumen modification 
increased the resistance against shear stresses. Highway pavement is highly susceptible to deformation under heavy vehicle traffic and high temperatures. It is therefore crucial to examine experimental data relating to these conditions. In this study, the complex shear modulus and wheel tracking parameters at low speeds representing heavy vehicle traffic indicated that, at high temperatures of $60-65^{\circ} \mathrm{C}$, the $\mathrm{B}-4-\mathrm{WP}$ exhibited as much resistance to deformation as the $6 \%$ modified bitumens.

An evaluation of the phase angle values - which is a indicator of the bitumen's viscoelastic behavior against shear stresses-indicates that the use of $2 \%$ and $4 \%$ additives reduced the bitumen's phas eangle. Thus, the addition of these ratios of additives to the bitumen enhances its resistance against permanent deformations. When the additive ratio was increased to $6 \%$, a sudden increased was observed in the phase angle value, meaning that the bitumen's elasticity decreased. Especially under conditions of heavy vehicle traffic and high temperature, the phase angle values of the B, B-6-WP and B-2-WP were nearly 90 degrees, meaning that the bitumens exhibited an almost entirely viscous behavior. According to the results of the BBR test, modification generally improved the low temperature performance of bitumens relative to the pure bitumen; however, this improvement was noticeable up to a modification ratio of $4 \%$. Above $4 \%$, the creep stiffness value increased, while the m-value decreased. This indicated that modifying the bitumen with higher ratios of waste HDPE did not have a positive effect, in terms of improving the low temperature performance.

An evaluation of all test result sobtained within the scope of the study indicates that under conditions of heavy traffic and high temperature, the modification of the bitumen by upto $4 \%$ waste HDPE has led to positive results in terms of sensitivity to temperature,viscosity, complex shear modulus, Wheel tracking parameter, viscoelastic behavior and low temperature performance. The use of additives at a ratio of $4 \%$, in particular, not only helped harden the bitumen, but also allowed the mixture and compaction temperatures of the bitumen to be within acceptable levels. In addition, the bitumen also gained resistance against wheel tracking deformations, while its level of elasticity was preserved. The bitumen also gained the most resistance against thermal cracks with $4 \%$ additive.

\section{Funding}

This research was sponsored by the BAP (Scientific Research Projects Coordination Unit of Akdeniz University, Turkey) with the project code: FBA-2015-189. 


\section{References}

Maashan, N.S., Karim, M.R. 2013. Investigating the Rheological Properties of Crumb Rubber Modified Bitumen and its Correlation with Temperature Susceptibility.Materials Research, 16(1): 116-12

Topal, A.2010.Evaluation of the properties and microstructure of plastomeric polymer modified bitumens. Fuel Processing Technolog, Vol. 91: 45-51

Solouki, A., Muniandy, R., Hassim, S., Khredmand,B. 2015.Rheological Property Investigation of Various Sasobit-modified Bitumen, Petroleun Science and Technology,Vol.33: 773-779

Oner, J., Sengoz, B., Rija, S.F., Topal, A., 2016. Investigation of the rheological properties of elastomeric polymer-modified bitumen using warm-mix asphalt additives, Road Materials and Pavement Design, Vol.18: $1-18$

Rossi O.C., Spadafora A., Teltayev B., İzmailova G., Amerbayev Y., Botototti V., 2015. Polymer modified bitumen: Rheological properties and structural characterization, Colloids and Surfaces A: Physicochemical and Engineering Aspects, 480: 390-397

Silva, J., Lucena, L., Rodrigues, J., Carvalho, M., Costa, D. 2015.Use of Micronized Polyethylene Terephthalate (Pet) Waste in Asphalt Binder, Petroleum Science and Technology.33: 1532-2459

García-Morales M., Partal P., Navarro F.J., Gallegos C., 2006. Effect of waste polymer addition on the rheology of modified bitumen, Fuel ; 85 (7-8): 936-943

Köfteci S., Ahmedzade P., Kultayev B.,2014. Performance evaluation of bitumen modified by various types of waste plastics, Construction and Building Material ; 73: 592-602

Modarres A., Hamedi H., 2014. Effect of waste plastic bottles on the stiffness and fatigue properties of modified asphalt mixes, Materials\&Design , 61: 8-15

Hasan MRM., Colbert B, You Z, Jamshidi A, Heiden PA, Hamzah MO, 2016. A simple treatment of electronicwaste plastics to produce asphalt binder additives with improved properties, Construction and Building Materials; 110: 79-88

Gibreil H.A.A., Feng C.P., 2017, Effects of high-density polyethylene and crumb rubber powder as modifiers on properties of hot mix asphalt, Construction and Building Material ; 142: 101-108

Nejad F.M., Azarhoosh, A., Hamedi, G.H.,2014. Effect of high density polyethylene on the fatigue and rutting performance of hot mix asphalt - a laboratory study. Road Materials and Pavement Design; 15(3): 746-756

Abdulrahman,W.M.N.W., Wahab, A.F.A., Zulkifly. 2014. Behaviour of asphalt mixtures with recycled polyethylene terephthalate and high density polyethylene pellet as fine aggregate replacement. In 
Proceedings of the MUCET 2014 (Malaysian Technical Universities Conference on Engineering \& Technology), Melaka, Malaysia, 10-11 November 2014.

Hsuan YG, McGrath Timothy J, 1999. HDPE Pipe: Recommended Material Specifications and Design Requirements”, NHCRP Report, Report No. 429, National Academy Press

Lu X, Isacsson U., 1997. Characterization of SBS polymer modified bitumen -comparison of conventional methods and DMA, Journal of Testing Evaluation, 25(4): 383-390.

Tapkın, S., Çevik, A., Özcan, Ş.2012.Utilising Neural Networks and Closed Form Solutions to Determine Static Creep Behaviour and Optimal Polypropylene Amount in Bituminous Mixtures. Materials Research, 2012, 15 (6): $865-883$

Nichols C., editor, 2006.Analysis of Available Data for Validation of Bitumen Tests.Bitval Project Report Phase $: 1$, FEHRL.

Chun Wang, PeiwenHao, Fang Rua, Xiyan Zhang, Sanjeev Adhikari,2013. "Determination of the production temperature of warm mix asphalt by workability test" Construction and Building Materials, 48 : 1165-1170

EN 13399: Bitumen and Bituminous Binders - Determination of StorageStability of Modified Bitumen. European Standard, 2010. 


\section{List of figures}

Figure 1. The mixing-compaction temperatures for pure and WP modified bitumens

Figure 2. Complex shear modulus $\left(\mathrm{G}^{*}\right)$ for WP modified bitumens at $0.111 \mathrm{~Hz}(7 \mathrm{~km} / \mathrm{h})$

Figure 3. Complex shear modulus $\left(\mathrm{G}^{*}\right)$ for WP modified bitumens at $0.796 \mathrm{~Hz}(50 \mathrm{~km} / \mathrm{h})$

Figure 4. Complex shear modulus $\left(\mathrm{G}^{*}\right)$ for WP modified bitumens at $1.909 \mathrm{~Hz}(120 \mathrm{~km} / \mathrm{h})$

Figure 5. Phase angel $(\delta)$ for WP modified bitumens at $0.111 \mathrm{~Hz}(7 \mathrm{~km} / \mathrm{h})$

Figure 6. Phase angel $(\delta)$ for WP modified bitumens at $0.796 \mathrm{~Hz}(50 \mathrm{~km} / \mathrm{h})$

Figure 7. Phase angel ( $\delta)$ for WP modified bitumens at $1.909 \mathrm{~Hz}(120 \mathrm{~km} / \mathrm{h})$

Figure 8. Rutting parameters $\left(\mathrm{G}^{*} / \mathrm{sin} \delta\right)$ for WP modified bitumens at $0.111 \mathrm{~Hz}(7 \mathrm{~km} / \mathrm{h})$

Figure 9. Rutting parameters $\left(\mathrm{G}^{*} / \mathrm{sin} \delta\right)$ for WP modified bitumens at $0.796 \mathrm{~Hz}(50 \mathrm{~km} / \mathrm{h})$

Figure 10. Rutting parameters $\left(\mathrm{G}^{*} / \mathrm{sin} \delta\right)$ for WP modified bitumens at $1.909 \mathrm{~Hz}(120 \mathrm{~km} / \mathrm{h})$ 


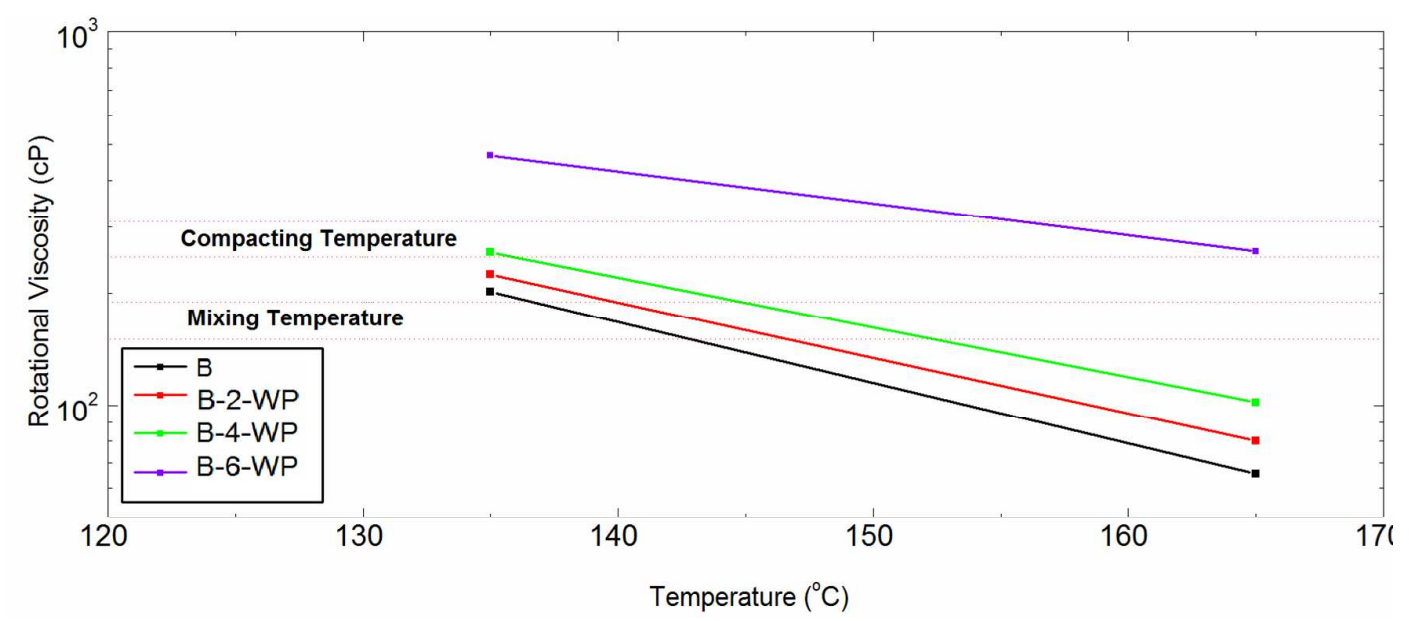

Figure 1. The mixing-compaction temperatures for pure and WP modified bitumens 


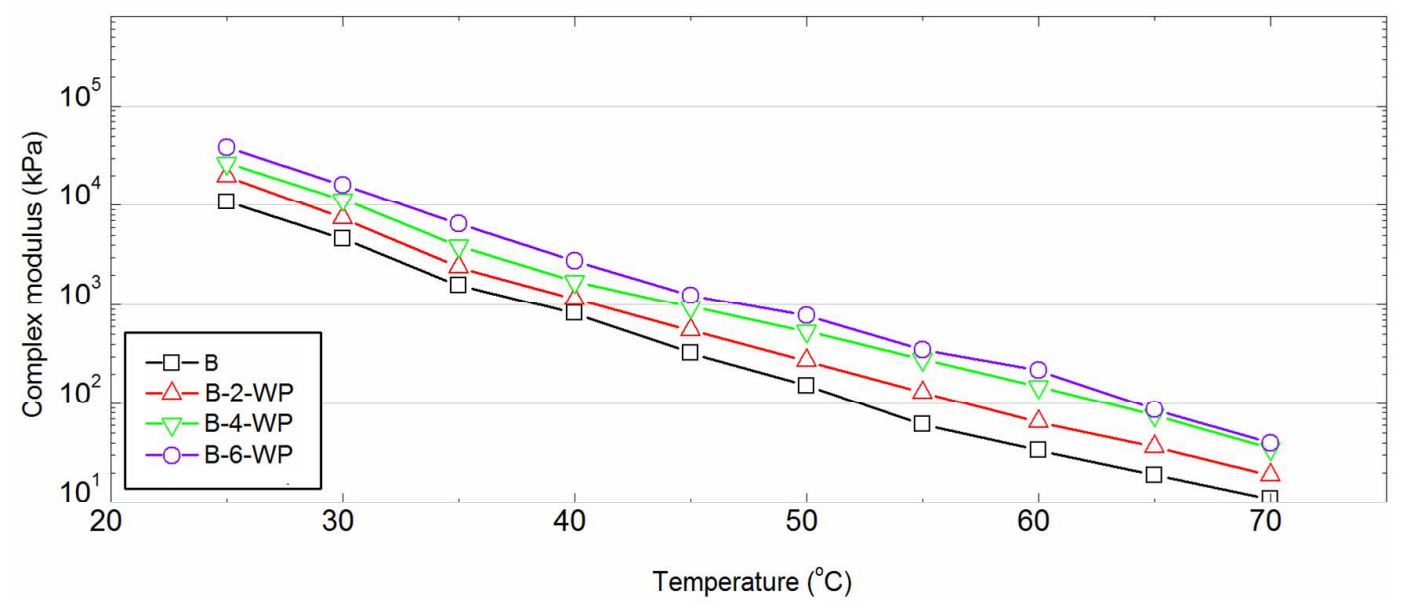

Figure 2. Complex shear modulus $\left(\mathrm{G}^{*}\right)$ for WP modified bitumens at $0.111 \mathrm{~Hz}(7 \mathrm{~km} / \mathrm{h})$ 


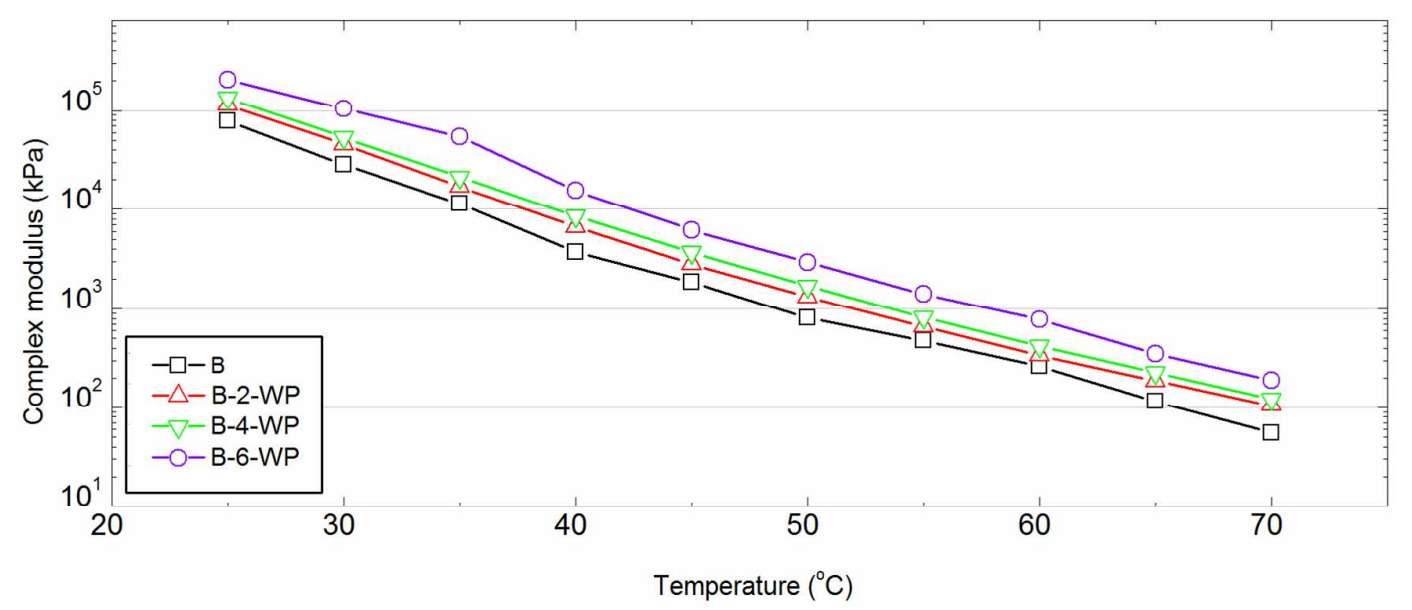

Figure 3. Complex shear modulus $\left(\mathrm{G}^{*}\right)$ for WP modified bitumens at $0.796 \mathrm{~Hz}(50 \mathrm{~km} / \mathrm{h})$ 


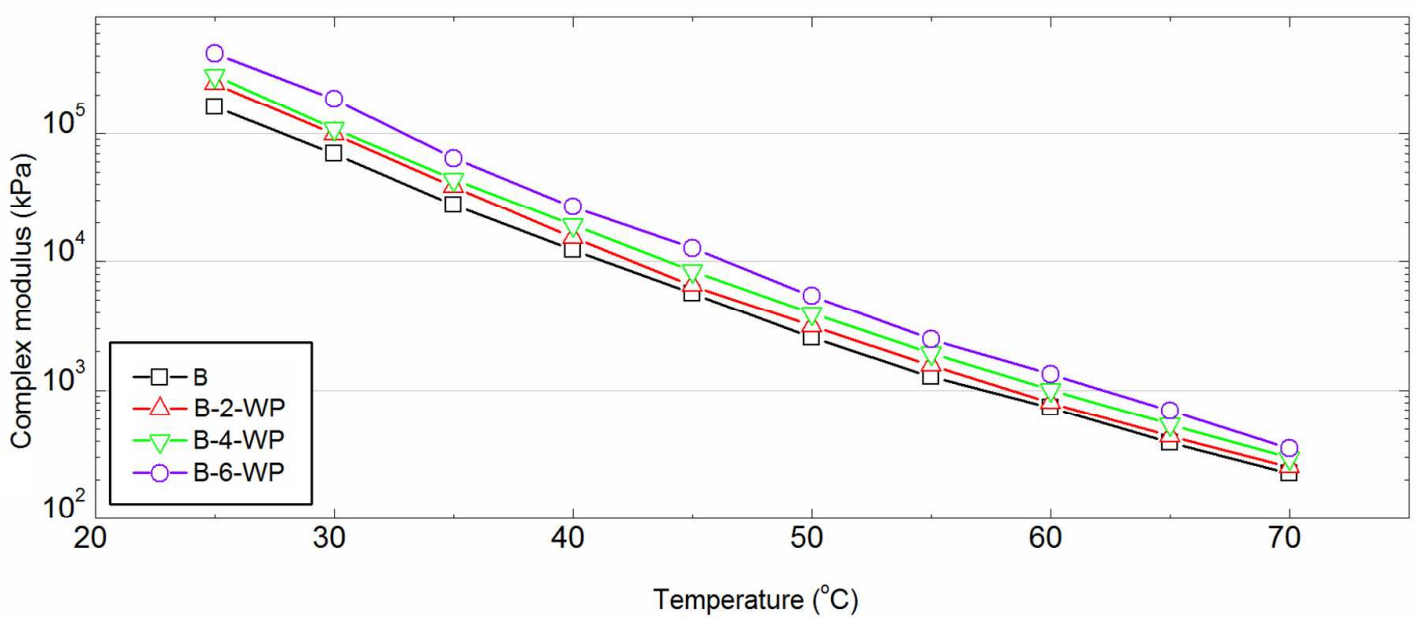

Figure 4. Complex shear modulus $\left(\mathrm{G}^{*}\right)$ for WP modified bitumens at $1.909 \mathrm{~Hz}(120 \mathrm{~km} / \mathrm{h})$ 


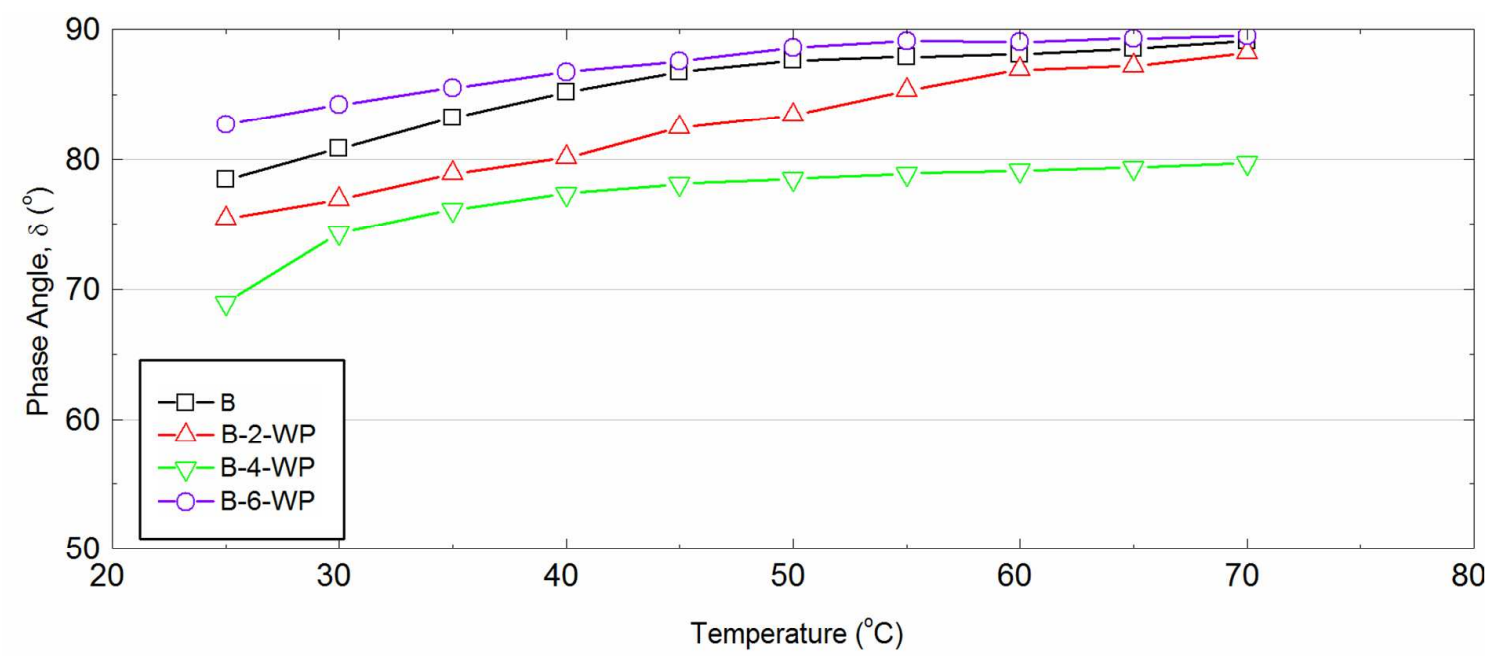

Figure 5. Phase angel $(\delta)$ for WP modified bitumens at $0.111 \mathrm{~Hz}(7 \mathrm{~km} / \mathrm{h})$ 


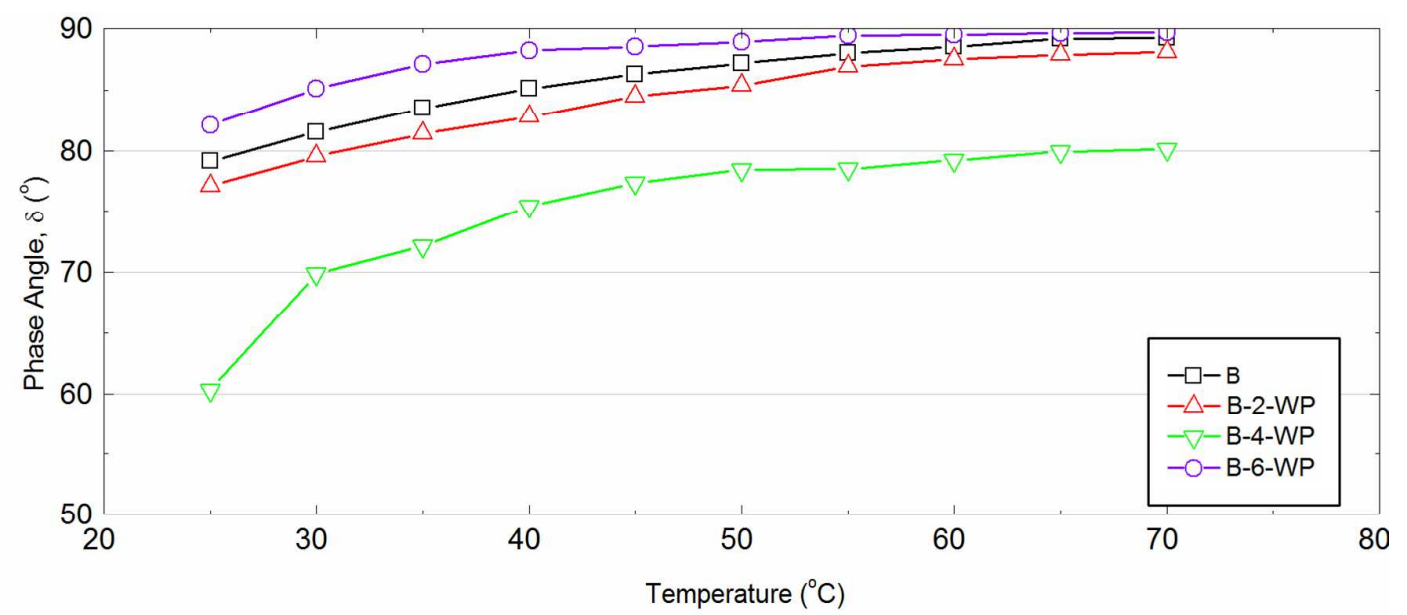

Figure 6. Phase angel $(\delta)$ for WP modified bitumens at $0.796 \mathrm{~Hz}(50 \mathrm{~km} / \mathrm{h})$ 


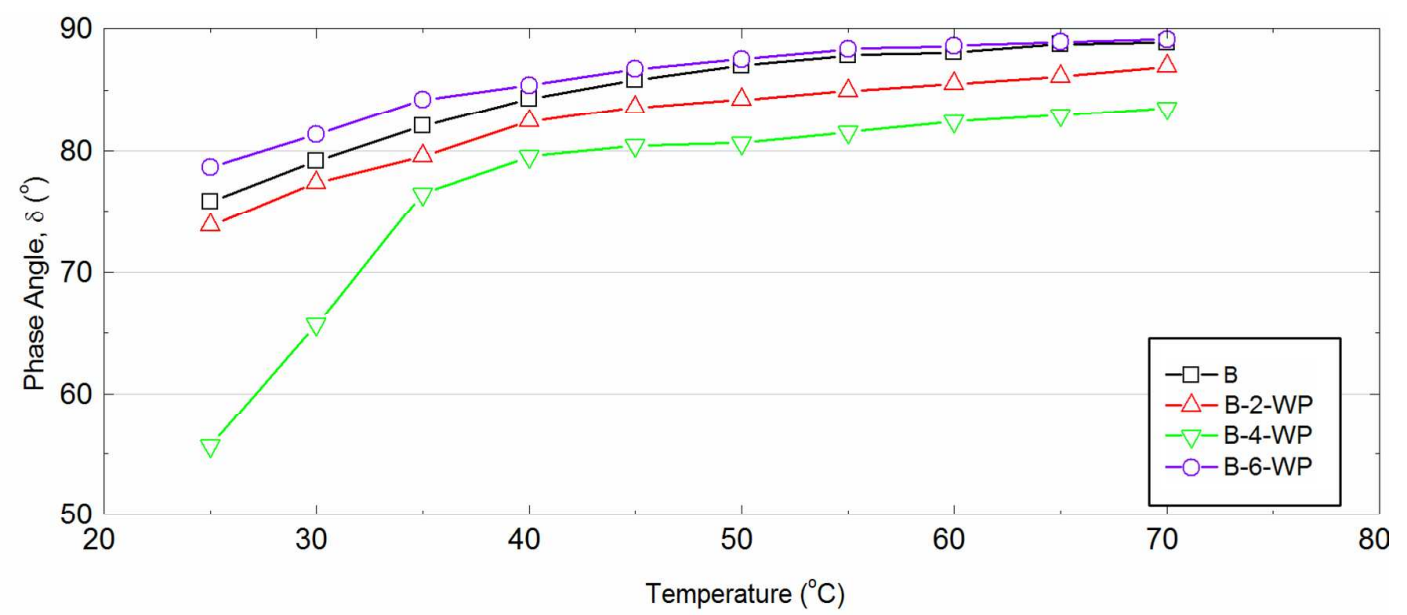

Figure 7. Phase angel ( $\delta)$ for WP modified bitumens at $1.909 \mathrm{~Hz}(120 \mathrm{~km} / \mathrm{h})$ 


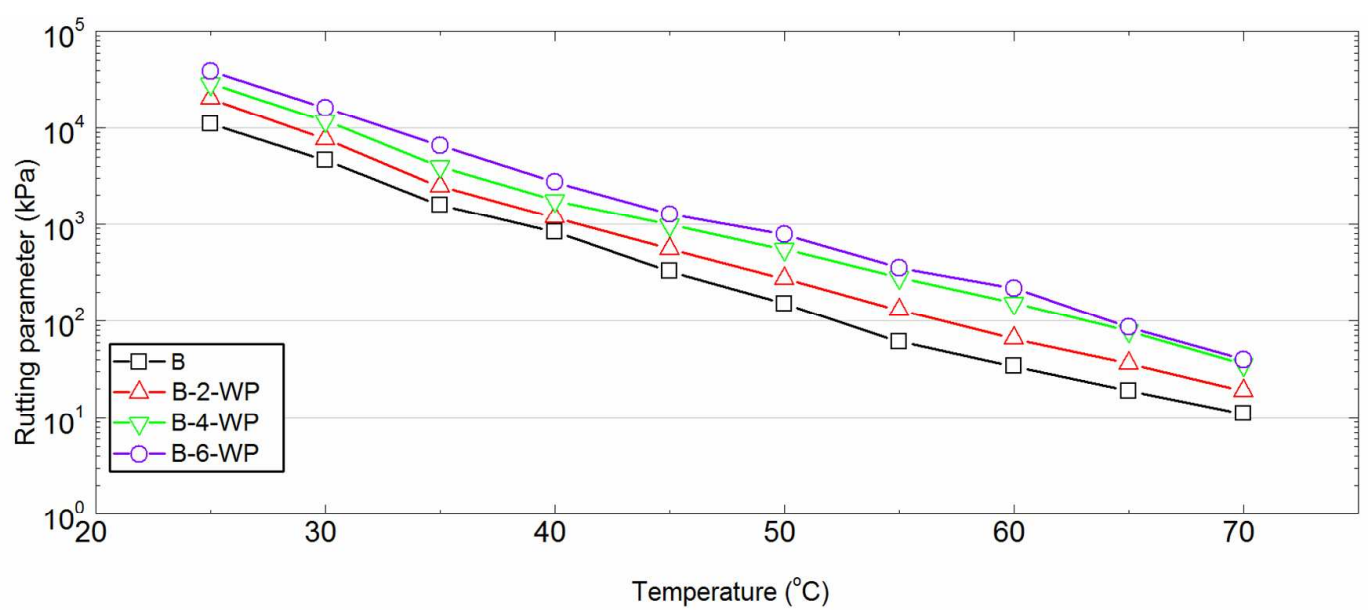

Figure 8. Rutting parameters $\left(\mathrm{G}^{*} / \mathrm{sin} \delta\right)$ for WP modified bitumens at $0.111 \mathrm{~Hz}(7 \mathrm{~km} / \mathrm{h})$ 


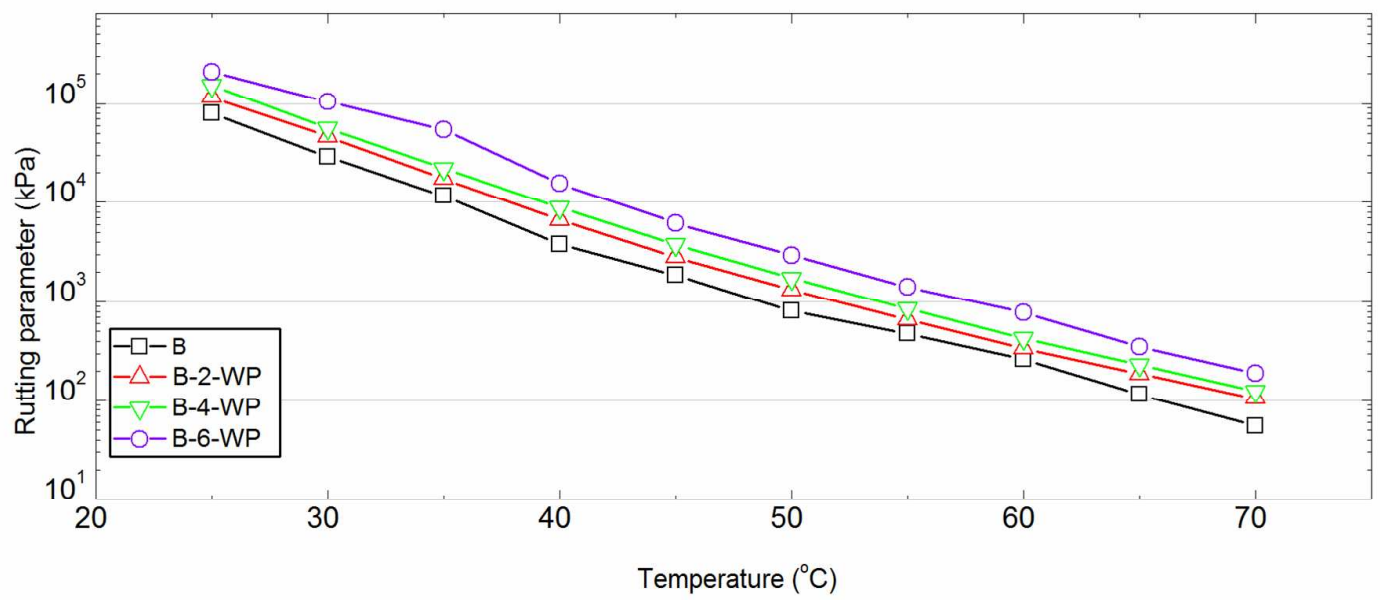

Figure 9. Rutting parameters $\left(\mathrm{G}^{*} / \mathrm{sin} \delta\right)$ for WP modified bitumens at $0.796 \mathrm{~Hz}(50 \mathrm{~km} / \mathrm{h})$ 


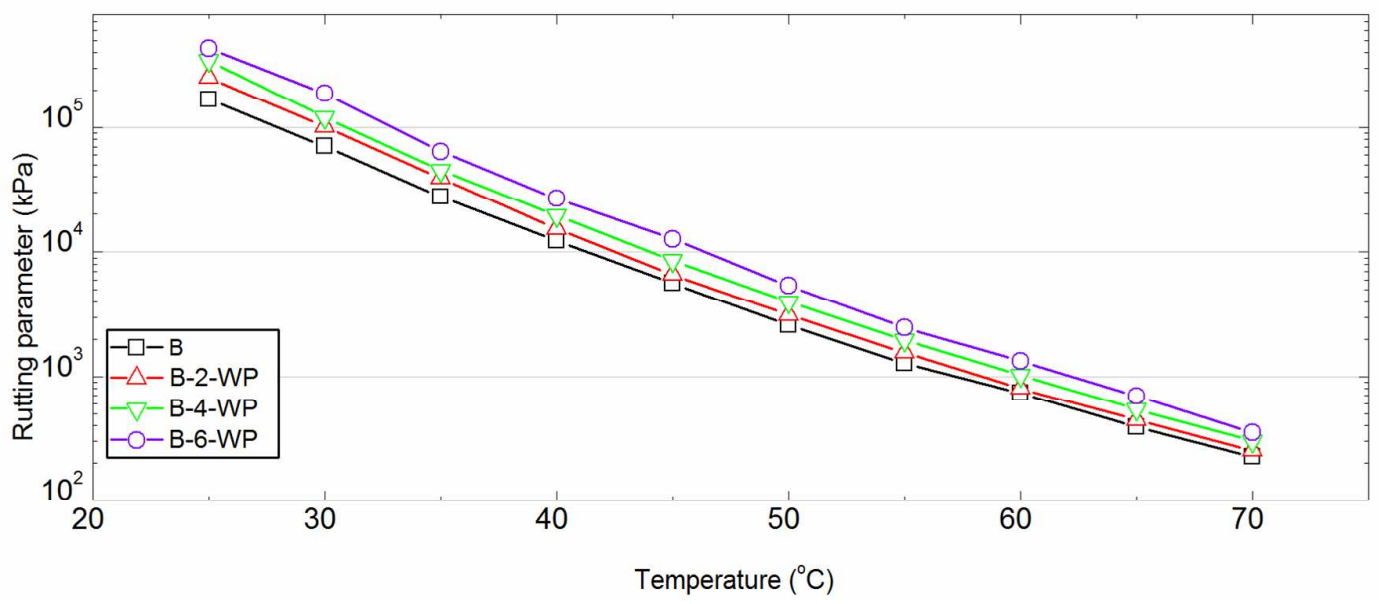

Figure 10. Rutting parameters $\left(\mathrm{G}^{*} / \mathrm{sin} \delta\right)$ for WP modified bitumens at $1.909 \mathrm{~Hz}(120 \mathrm{~km} / \mathrm{h})$ 


\section{List of tables}

Table 1. Physical properties of the pure bitumen

Table 2. Basic physical properties of the HDPE additive

Table 3. Conventional test results of the pure and WP modified bitumens before and after aging

Table 4. Storage stability test results of WP modifiedbitumens.

Table 5.Viscosity values of the pure and WP modified bitumens

Table 6. Test parameters used in the DSR test

Table 7. Creep stiffness and m-value of the pure and modified bitumens at a loading time $60 \mathrm{~s}$ and different temperatures 
Table 1. Physical properties of the pure bitumen

\begin{tabular}{llll}
\hline & Specification & Results & Specification limits \\
\hline Penetration $\left(25^{\circ} \mathrm{C} ; 0.1 \mathrm{~mm}\right)$ & ASTM D5 & 196.3 & $160-220$ \\
Softening point $\left({ }^{\circ} \mathrm{C}\right)$ & ASTM D36 & 41.2 & $35-43$ \\
Penetration index $(\mathrm{PI})$ & - & 0.396 & - \\
Specificgravity $\left(25^{\circ} \mathrm{C}, \mathrm{gr} / \mathrm{cm}^{3}\right)$ & ASTM D70 & 1.032 & - \\
\hline
\end{tabular}


Table 2. Basic physical properties of the HDPE additive

\begin{tabular}{ll}
\hline \multicolumn{1}{c}{ Property } & \multicolumn{1}{c}{ Value } \\
\hline Density $\left(\mathrm{g} / \mathrm{cm}^{3}\right)$ & 0.96 \\
Meltingpoint $\left({ }^{\circ} \mathrm{C}\right)$ & 135 \\
Meltflow $(\mathrm{g} / 10 \mathrm{~min})$ & $0.03-0.07$ \\
Tensile strength $\left(\mathrm{kg} / \mathrm{cm}^{2}\right)$ & 275 \\
Tensile strength, ultimate $\left(\mathrm{kg} / \mathrm{cm}^{2}\right)$ & 330 \\
\hline
\end{tabular}


Table 3. Conventional test results of the pure and WP modified bitumens before and after aging

\begin{tabular}{|c|c|c|c|c|}
\hline \multirow{3}{*}{ Properties } & \multicolumn{4}{|c|}{ Binder type } \\
\hline & \multicolumn{4}{|c|}{ Modified bitumens } \\
\hline & B & B-2-WP & B-4-WP & B-6-WP \\
\hline Penetration $\left(25^{\circ} \mathrm{C} ; 0.1 \mathrm{~mm}\right)$ & 196.3 & 165.7 & 137.8 & 71.4 \\
\hline Softening point $\left({ }^{\circ} \mathrm{C}\right)$ & 41.2 & 47.2 & 53.3 & 62.4 \\
\hline Penetration index ( PI ) & 0.39 & 1.81 & 2.77 & 2.48 \\
\hline Ductility $\left(25^{\circ} \mathrm{C}, \mathrm{cm}\right)$ & $>100$ & 94 & 90 & 78 \\
\hline \multicolumn{5}{|l|}{ After aging (RTFOT) } \\
\hline Change of mass $(\%)$ & 0.69 & 0.66 & 0.48 & 0.41 \\
\hline Penetration $\left(25^{\circ} \mathrm{C} ; 0.1 \mathrm{~mm}\right)$ & 104.6 & 98.7 & 95.4 & 43.2 \\
\hline Retained penetration $(\%)$ & 53.29 & 59.56 & 69.23 & 60.50 \\
\hline Softening point $\left({ }^{\circ} \mathrm{C}\right)$ & 43.1 & 44.6 & 49.1 & 53.4 \\
\hline Change in softening point $\left({ }^{\circ} \mathrm{C}\right)$ & -1.9 & -2.6 & -4.2 & -9.00 \\
\hline
\end{tabular}


Table 4. Storage stability test results of WP modified bitumens.

\begin{tabular}{lllllll}
\hline Binder & $\begin{array}{l}\text { Penetration } \\
\text { bottom part, } \\
0.1 \mathrm{~mm}\end{array}$ & $\begin{array}{l}\text { Penetration } \\
\text { top part, } \\
0.1 \mathrm{~mm}\end{array}$ & $\begin{array}{l}\text { Difference in } \\
\text { penetration between } \\
\text { bottom and top } \\
\text { part, 0.1mm }\end{array}$ & $\begin{array}{l}\text { Softening point } \\
\text { bottom } \\
\text { part, }{ }^{\circ} \mathrm{C}\end{array}$ & $\begin{array}{l}\text { Softening } \\
\text { point top } \\
\text { part, }{ }^{\circ} \mathrm{C}\end{array}$ & $\begin{array}{l}\text { Difference in } \\
\text { softening point } \\
\text { between bottom } \\
\text { and top part, }{ }^{\circ} \mathrm{C}\end{array}$ \\
\hline B-2-WP & 160 & 162 & 2 & 50 & 49 & 1 \\
B-4-WP & 132 & 134 & 2 & 57.5 & 56 & 1.5 \\
B-6-WP & 66 & 69 & 3 & 65 & 63.5 & 1.5 \\
\hline
\end{tabular}


Table 5. Viscosity values of the pure and WP modified bitumens

\begin{tabular}{llllllll}
\hline \multirow{2}{*}{ Binder types } & \multicolumn{2}{c}{ Rotational viscosity $(\mathrm{cP})$} & \multicolumn{2}{c}{$\eta_{\mathrm{m}} / \eta_{\mathrm{B}}{ }^{*}$} & \multicolumn{2}{c}{ Temperature range $\left({ }^{\circ} \mathrm{C}\right)$} \\
\cline { 2 - 8 } & \multicolumn{1}{c}{$135^{\circ} \mathrm{C}$} & \multicolumn{2}{c}{$165{ }^{\circ} \mathrm{C}$} & $135{ }^{\circ} \mathrm{C}$ & $165{ }^{\circ} \mathrm{C}$ & Mixing & Compaction \\
\hline B & 207.5 & 67.5 & 1 & 1 & $136-144$ & $124-130$ \\
B-2-WP & 225 & 80 & 108 & 1.16 & $140-146$ & $126-131$ \\
B-4-WP & 257.5 & 102.5 & 1.24 & 1.52 & $145-153$ & $129-136$ \\
B-6-WP & 467.5 & 258.13 & 2.25 & 3.82 & $180-192$ & $155-166$ \\
\hline
\end{tabular}


Table 6. Test parameters used in the DSR test

\begin{tabular}{ll}
\hline Test parameters & \\
\hline Loadingtype & Controlledstrain \\
Frequencies, $\mathrm{Hz}(\mathrm{rad} / \mathrm{sn})$ & $0.111 \mathrm{~Hz}(0.7 \mathrm{rad} / \mathrm{s}), 0.796 \mathrm{~Hz}(5 \mathrm{rad} / \mathrm{s}), 1.909 \mathrm{~Hz}(12 \mathrm{rad} / \mathrm{s})$ \\
Trafficspeedsequivalentfrequencies, $\mathrm{km} / \mathrm{h}$ & Low $(7 \mathrm{~km} / \mathrm{h})$, Medium, $50 \mathrm{~km} / \mathrm{h}, \mathrm{High}, 120 \mathrm{~km} / \mathrm{h}$ \\
Temperatures, ${ }^{\circ} \mathrm{C}$ & $25,30,35,40,45,50,55,60,65,70$ \\
Diameterspindle, mm. & 25 \\
Testinggap, mm. & 1 \\
\hline
\end{tabular}


Table 7. Creep stiffness and $m$-value of the pure and modified bitumens at a loading time $60 \mathrm{~s}$ and different temperatures

\begin{tabular}{lcccccc}
\hline \multirow{2}{*}{ Bindertypes } & \multicolumn{3}{c}{ Creepstiffness (MPa) } & \multicolumn{3}{c}{ m-value } \\
& $-15^{\circ} \mathrm{C}$ & $-25^{\circ} \mathrm{C}$ & $-35^{\circ} \mathrm{C}$ & $-15^{\circ} \mathrm{C}$ & $-25^{\circ} \mathrm{C}$ & $-35^{\circ} \mathrm{C}$ \\
\hline B & 69.7136 & 224.3489 & 537.1688 & 0.342601 & 0.300712 & 0.273294 \\
B-2-WP & 57.4906 & 196.2487 & 495.0245 & 0.386782 & 0.311834 & 0.301604 \\
B-4-WP & 51.3792 & 182.3066 & 474.3478 & 0.412637 & 0.336792 & 0.332794 \\
B-6-WP & 63.2876 & 194.5543 & 486.2674 & 0.359580 & 0.297235 & 0.292643 \\
\hline
\end{tabular}

